\title{
Discursos e regimes de verdade em enunciados sobre o sujeito quilombola na mídia
}

Discourse and truth regulations in statements about the quilombola subject in the media

Discursos y regímenes de verdad en enunciados sobre el sujeto quilombola en los medios de comunicación

\author{
Claudemir Sousa ${ }^{1}$ \\ Universidade Estadual Paulista - UNESP \\ claudemir201089@hotmail.com
}

\begin{abstract}
RESUMO: Os conceitos atuais de quilombo e quilombola são resultantes de embates históricos em torno da manipulação da memória social brasileira acerca da participação do negro na formação do povo brasileiro. Assim, neste artigo, analisaremos quais regimes de verdade sustentaram a produção enunciativa sobre o sujeito quilombola na mídia. Para tanto, recorreremos a dois enunciados do jornal $O$ Estado do Maranhão que têm como objeto o quilombola. A ancoragem teórica para essas análises são os Estudos Discursivos Foucaultianos, assentados na proposta teórico-metodológica de Michel Foucault, que toma os discursos em sua dimensão histórica para analisar os enunciados em sua dispersão e no campo adjacente do qual fazem parte. Nesse sentido, além de nos referirmos a outros enunciados, também nos apoiamos em outros autores que contribuem para essa discussão. Concluímos que os discursos da mídia acerca do sujeito quilombola na história de construção da sociedade brasileira elaboram regimes de verdade que se pautam no acontecimento da assinatura da Lei Áurea, em 13 de maio de 1888, e nas lutas pela liberdade dos escravizados travadas por Zumbi dos Palmares, morto em 20 de novembro de 1695.
\end{abstract}

Palavras-chave: Discurso; Verdade; Sujeito quilombola; Mídia.

ABSTRACT: The current concepts of quilombo and quilombola are the result of historical clashes over the manipulation of Brazilian social memory about the participation of black people in the formation of the Brazilian people. Thus, in this article we will analyze which truth regulations sustained the enunciating production about the quilombola subject in the media. To this end, we used two statements from the newspaper $O$ Estado do Maranhão whose object is the quilombola. The theoretical approach for these analyzes are the Foucaultians Discursive Studies, based on Michel Foucault's theoretical-methodological proposal, which takes the discourses in their historical dimension to analyze the statements in their dispersion and in the adjacent field of which they are part. In this sense, in addition to referring to other statements, we will also appeal to other authors who contribute to this discussion. We concluded that the media discourses about the quilombola subject in the history of the construction of Brazilian society elaborate truth regulations that are guided by the signing of the Lei Áurea, on May

\footnotetext{
${ }^{1}$ Doutor em Linguística e Língua Portuguesa pela Universidade Estadual Paulista "Júlio de Mesquita Filho", campus de Araraquara (UNESP/FCLar). Mestre em Linguística pela Universidade Federal da Paraíba (UFPB). Graduado em Letras: língua portuguesa e língua inglesa pela Universidade Federal do Maranhão (UFMA).
} 
13, 1888, and in the struggles for the freedom of the en slaves, guided by Zumbi dos Palmares, killed on November 20, 1695.

Keywords: Discourse; Truth; Quilombola subject; Media.

RESUMEN: Los actuales conceptos de quilombo y quilombola son el resultado de choques históricos vinculados a la manipulación de la memoria social brasileña en relación a la participación de los negros en la formación del pueblo brasileño. Así, en este artículo analizaremos qué regímenes de verdad sustentaron la producción enunciativa sobre el sujeto quilombola en los medios de comunicación. Para ello, recurriremos a dos artículos del periódico $O$ Estado do Maranhão que tienen como objeto la quilombola. El anclaje teórico de estos análisis serán los Estudios Discursivos Foucaultianos, basados en su propuesta teórico-metodológica, que toma los discursos en su dimensión histórica para analizar los enunciados en su difusión y en el campo adyacente del que forman parte. En este sentido, además de referirnos a otras afirmaciones, nos apoyaremos también en otros autores que contribuyan a esta discusión. Concluimos que los discursos de los medios de comunicación relacionados con el sujeto quilombola elaboran, en la historia de la construcción de la sociedad brasileña, regímenes de verdad basados en la firma de la Ley Áurea, el 13 de mayo de 1888 y en las luchas por la libertad de los esclavos encabezadas por Zumbi dos Palmares, quien falleció el 20 de noviembre de 1695.

Palabras clave: Discurso; Verdad; Sujeto quilombola; Medios de comunicación. 


\section{Introdução}

Em diferentes momentos políticos brasileiros, os sujeitos quilombolas se viram envolvidos em embates históricos com aqueles que lhes negam diretos essenciais que são extensivos a outras camadas da população. Tal fato se observa, particularmente, em dois momentos da história recente do Brasil, quais sejam: a período de Ditadura Militar, no qual diversas famílias residentes em distintas comunidades quilombolas foram remanejadas dos seus territórios para implantar uma base de lançamento de foguetes em Alcântara, Maranhão (MA), e em 2018, ano de eleições presidenciais no Brasil, no qual circulou na internet um vídeo com falas do então candidato a presidente da República, Jair Bolsonaro, sobre quilombolas, proferida no Clube Hebraica, na Zona Sul do Rio de Janeiro (RJ), na qual ele diz o que segue: "eu fui num quilombo em Eldorado Paulista. Olha, o afrodescendente mais leve de lá pesava sete arrobas. Não fazem nada. Eu acho que nem para procriadores eles servem mais. Mais de 1 bilhão de reais por ano gastados com eles".

Nesse enunciado, circulam discursos hierarquizantes que inferiorizam os quilombolas e os vinculam a uma concepção animalesca, visto que a arroba é utilizada como unidade de medida para pesagem de animais bovinos e suínos, passando a ser extensiva ao quilombola como estratégia de luta política contra o reconhecimento de direitos a esse sujeito. Para tanto, recorre-se a saberes eugenistas e racistas que circulam no Brasil desde a virada do século XIX para o XX, preconizando o branqueamento da nação a partir do cruzamento das raças (SCHWARCZ, 1993).

Esse enunciado também integra um conjunto enunciativo no interior do qual diversos sujeitos se posicionam contrariamente às medidas recentes que tentam assegurar cidadania às populações quilombolas, sob a alegação de que o investimento em políticas públicas para essa população acarreta "gastos". A existência dessas populações no Brasil, habitando territórios nos quais realizam atividades de subsistência, também causa indignação naqueles que desejam um tipo de desenvolvimento ao país nos moldes do capitalismo.

Em vista da existência de diferentes operações discursivas que tentam inferiorizar o sujeito quilombola em relação aos demais sujeitos e despossuí-los de sua identidade, este estudo objetiva analisar os regimes de verdade que sustentam os discursos acerca desse sujeito nos enunciados da mídia. Essas operações discursivas se sustentam em diferentes regimes de verdades (FOUCAULT, 2013), que, sendo históricas e socialmente marcadas, sofrem mutações, fazendo com que a história da participação dessa camada da população na 
formação do povo brasileiro seja objeto de disputas pelo privilégio de manipular a memória social (LE GOFF, 1990).

Desde os contatos iniciais dos europeus com as populações do continente africano, que seriam escravizadas, o território e os sujeitos que os habitavam eram denominadas genericamente por termos como "guinés" e "etíopes". Posteriormente, o termo "escravo" serviu para despersonalizar a procedência étnica desses sujeitos, que, ao chegar ao território que hoje é o Brasil, eram batizados com nomes "cristãos" para se tornar "ladinos", deixando de ser considerados como "boçais", e misturados para dificultar a comunicação em suas línguas maternas. O termo "escravo" provém de "eslavo", gentílico utilizado para se referir ao povo das regiões do Mar Báltico, que também foi submetido à escravidão antes que essa prática fosse associada majoritariamente aos negros.

Já os temos "mocambo", "mocambeiro", "quilombo" e "quilombola" possuem diferentes movimentos históricos de serem ora uma designação genérica e atribuída do exterior, ora uma forma de denominação abraçada pelo sistema jurídico, pelos movimentos sociais e também pelos agentes sociais a quem designam, como forma de ter a proteção da lei e acesso a diretos constitucionalmente assegurados.

Primeiramente, quanto à história desses termos e seus sentidos etimológicos, referemse aos grupos formados, inicialmente, por escravizados fugidos. A intensidade da formação de quilombos no Brasil se explica, entre outras coisas, pela grande quantidade de escravizados vindos para esse país, pela longa duração do regime escravista, pela localização de fazendas escravistas em zonas de matas, para onde os quilombolas fugiam, e pela ocorrência de guerras e revoltas populares. A fuga, resultando na formação dos quilombos, foi a mais típica forma de resistência ao escravismo, mas não a única, visto que quilombos também se formavam pela ocupação de terras abandonadas por fazendeiros falidos ou "doação" por fazendeiros e ordens religiosas.

$\mathrm{Na}$ América Portuguesa, tais grupos eram denominados de "quilombos" e "mocambos", e seus membros de "quilombolas", "calhambolas" ou "mocambeiros" (REIS; GOMES, 2012). A primeira denominação para essas comunidades no Brasil era "mocambo" e, depois, foram denominadas de "quilombos". Esses termos eram utilizados na África Central para designar acampamentos improvisados utilizados para guerra ou prisão de escravizados. O termo "quilombo" era associado, no século XVII, aos guerreiros imbangalas (jagas) e aos rituais de iniciação por eles praticados. "Mocambo", ou "mukambu", por seu turno, significava, nas línguas kimbundu e kicongo, da África Central, "pau de fieira", referindo-se aos suportes utilizados na construção de acampamentos (GOMES, 2015). Ao serem 
mobilizados na América Portuguesa, não necessariamente eram utilizados para autodenominação.

Nas áreas de colonização espanhola, inglesa e francesa nas Américas, que receberam escravizados da África Central, haviam outras denominações, quais sejam: palenques, cumbes, etc., na América Espanhola; marrons, na Inglesa; grand marronage (fuga em grupo), petit marronage (fuga individual), na Francesa. Assim, compreende-se que essa denominação era uma atribuição da administração portuguesa, referindo-se às estratégias militares de acampamento e aos prisioneiros de guerra na África e, posteriormente, às comunidades de fugitivos no Brasil. O termo "quilombo" só aparece na documentação colonial portuguesa no final do século XVII, sendo utilizado o termo "mocambo" antes. O primeiro registro de um mocambo no Brasil é de 1575, na Bahia (BA).

Finalmente, as categorias jurídicas de quilombo e quilombola são engendradas em diferentes momentos da história brasileira. Na legislação do Brasil Colônia era considerado quilombo o agrupamento formado por cinco (5) escravos fugidos. Já na legislação do Império, esse número foi reduzido para dois (2) (ARRUTI, 2003). Esse primeiro movimento histórico de definição jurídica de quilombo teve função repressiva.

Nos anos de 1980, com a abertura política, após muitos anos de ditadura militar, a proximidade da comemoração do centenário da abolição da escravidão e o movimento Nacional Constituinte, criam-se condições para a formulação de uma categoria jurídica para quilombo e quilombola que se assenta nos princípios democráticos que deram origem à Constituição Federal de 1988, pela aprovação do artigo $n^{\circ} 68$ no Ato das Disposições Constitucionais Transitórias (ADCT), reconhecendo a propriedade das terras aos seus ocupantes, mas que só teve validade prática após a regulamentação por Leis, Decretos e Instruções Normativas.

Nesse dispositivo constitucional, os regimes de verdade (FOUCAULT, 2013) que sustentam a formulação desse conceito são fabricados por políticos, militantes do movimento negro e pesquisadores de diferentes áreas do conhecimento, que se reportavam quase que exclusivamente ao Quilombo de Palmares e propuseram operações de tombamento patrimonial, que não condiziam com os anseios dos quilombolas, que enfrentavam disputas territoriais com empresários, mas foram essenciais para dar lugar a esses sujeitos na memória social brasileira e assegurar uma série de direitos.

Nesse sentido, em vista da relevância de compreendermos a história dos sujeitos quilombolas na formação política e social do Brasil, esta análise dos regimes de verdade que sustentam os discursos acerca do sujeito quilombola na mídia apoia-se em dois enunciados do 
jornal $O$ Estado do Maranhão, que têm como objeto de formulação o quilombola, e está ancorada nos Estudos Discursivos Foucaultianos, que se assentam na proposta teóricometodológica de Michel Foucault. Para esse autor, os discursos devem ser analisados em sua dimensão histórica e os enunciados são caracterizados pela sua dispersão e pertencimento a um campo associado. Por isso, iremos nos referir a outros enunciados que estão no domínio de memória sobre o sujeito quilombola, bem como buscaremos respaldo em autores que contribuem para essa discussão em diferentes áreas do saber.

Nossa discussão está organizada da seguinte forma: na sessão que segue, discutiremos as contribuições de Foucault $(2002$, 2008, 2013) para pensarmos os conceitos de discurso, sujeito, verdade e memória, bem como os conceitos de comemoração e rememoração, a partir das discussões de Le Goff (1990). Em seguida, analisaremos as materialidades que compõem o corpus deste estudo e, por fim, apresentaremos as considerações finais.

\section{Considerações teóricas sobre o discurso, a verdade e a memória}

Há cerca de 20 anos, pesquisadores da área de Letras e Linguística no Brasil têm se interessado pela obra do francês Michel Foucault para investigar a relação do discurso com o social, o histórico, o cultural e o político em práticas que entrelaçam saber e poder na construção do sujeito. Essa investigação percorreu diferentes caminhos no Brasil e na França e tem auxiliado nas pesquisas sobre distintos objetos. De nossa parte, a análise aqui proposta tem como objeto o sujeito quilombola, para compreendermos os regimes de verdades (FOUCAULT, 2013) que sustentam a produção enunciativa acerca desse sujeito na mídia. Por essa razão, discutiremos os conceitos de discurso, sujeito, verdade e memória a partir das formulações foucautianas.

Inicialmente, destaca-se que, na obra de Foucault, o discurso pode ser compreendido como unidade intermediária da análise arqueológica por ele proposta, visto que, em sua concepção, o discurso é "um conjunto de enunciados, na medida em que se apoiem na mesma formação discursiva" (FOUCAULT, 2008, p. 132). Nesse sentido, o enunciado e a formação discursiva (FD) constituem unidades de menor e de maior dimensão, respectivamente, em relação ao que é o discurso, visto que a FD constitui um conjunto enunciativo, ao passo que o enunciado é a menor unidade de análise e se caracteriza (a) pela sua relação com um referencial, que constitui sua condição de emergência; (b) pela relação com o sujeito, 
compreendido como uma posição vazia e possível de ser ocupada; (c) pela existência de um domínio associado, do qual faz parte; e (d) pela sua existência material.

Nesse sentido, as materialidades jornalísticas que tomamos para análise constituem enunciados por estarem ligadas às condições históricas que possibilitaram a emergência das discussões sobre o sujeito quilombola nos anos de 1970/80, delinearem determinadas posições para esse sujeito, estarem inseridas em um campo adjacente sobre esse objeto discursivo, na dispersão que lhes caracteriza, e possuírem uma existência material.

Além disso, o discurso pode ser compreendido como fato linguístico, mas que também é um jogo polêmico e estratégico, "de ação e reação, de pergunta e resposta, de dominação e de esquiva, como também de luta" (FOUCAULT, 2002, p. 9), visto que, no caso em pauta, os discursos sobre o sujeito quilombola na mídia podem ser analisados a partir dos embates em torno da memória social brasileira e das posições que se determinam para os sujeitos envolvidos nessa luta.

O conceito de sujeito, por seu turno, além de ser um espaço vazio e possível de ocupar, é compreendido por Foucault (2002) como não essencialista, já que ele não é totalmente acabado, mas constituído na história, fundado e refundado a cada momento e sustentado por diferentes regimes de verdade (FOUCAULT, 2013). É por essa razão que podemos compreender que o sujeito quilombola é fundado na história a partir de verdades que se apoiam em formas discursivas como a jurídica.

No pensamento de Foucault, o conceito de verdade é compreendido como um desejo, decorrendo desse conceito a noção de "vontade de verdade", por alusão à vontade de potência, de Nietzsche; como um jogo, resultando na noção de jogos de verdade; e também como um regime ou política, quando da proposição da noção de regimes de verdade, para tratar da construção histórica e diferenciação da verdade em domínios de enunciação e dos procedimentos para a sua obtenção, como confissão, inquérito etc. (FOUCAULT, 2002).

Interessa-nos, aqui, a relação da verdade com os discursos. Sobre isso, Foucault (2013, p. 54, grifos do autor) diz que se deve, "por 'verdade', entender um conjunto de procedimentos regulados para a produção, a lei, a repartição, a circulação e o funcionamento dos enunciados". Em sua concepção,

Cada sociedade tem seu regime de verdade, sua "política geral" de verdade: isto é, os tipos de discurso que ela acolhe e faz funcionar como verdadeiros; os mecanismos e as instâncias que permitem distinguir os enunciados verdadeiros dos falsos, a maneira como se sanciona uns e outros; as técnicas e os procedimentos que são valorizados para a obtenção da verdade; o estatuto daqueles que têm o 
encargo de dizer o que funciona como verdadeiro (FOUCAULT, 2013, p. 52, grifos do autor).

O que se denomina de "regimes de verdade" são esses procedimentos que regulam a produção, circulação e recepção dos enunciados. Tais regimes estão ligados a sistemas de poder, que fazem com que os enunciados sejam acolhidos ou não como verdadeiros. Essa política da verdade está centralizada na forma do discurso científico, nas instituições que a produzem e nos sujeitos que a legitimam, tais como: intelectuais, cientistas, jornalistas etc., com destacada posição social. Dessa forma, nas lutas pela manipulação da memória social sobre a participação do quilombola na formação da sociedade brasileira existem discursos que são valorizados e outros que são desprezados, construindo, assim, uma memória sobre esses sujeitos.

O conceito de memória é compreendido por Foucault (2008) no conjunto das regras que delimitam a formação discursiva (formação dos conceitos, formação dos objetos, formação das modalidades enunciativas e formação das estratégias) e está relacionado à regra da formação dos conceitos e à maneira como esses se organizam em formas de sucessão, tipos de correlação e esquemas retóricos, segundo os quais se podem combinar grupos de enunciados. Essa configuração do campo enunciativo compreende formas de coexistência, as quais delineiam um campo de presença, constituído por enunciados já formulados e que são retomados como verdade, discutidos, julgados, rejeitados ou excluídos; um campo de concomitância, constituído por enunciados referentes a domínios de objetos diferentes e pertencentes a tipos de discursos diferentes, mas que mantêm relação, seja para servir de modelo um para o outro, seja porque um é instância superior ao qual o outro está submetido; e um domínio de memória, constituído por enunciados que não são mais discutidos, mas em relação aos quais se estabelecem deslocamentos, continuidades ou descontinuidades.

O domínio de memória possibilita descrever a forma de organização de conceitos pertencentes a uma formação discursiva pela maneira que estão relacionados às formas de hierarquia e de subordinação que regem os enunciados. O conceito de memória formulado por Foucault (2008) foi ressignificado por Courtine (2009), e essa reformulação acabou sendo alvo de inúmeras apropriações confusas, como demonstrado em Sousa et al. (2016). Nesse texto, mostramos que, ao lado de reverberações bem conduzidas da noção de memória em autores que se filiam às concepções de Foucault (2008) e Courtine (2009), há confusões em autores que mobilizam a noção de interdiscurso como sinônima de memória e também que atribuem a noção de memória discursiva a Pêcheux quando, na verdade, a história da AD nos 
mostra que tal conceito foi desenvolvido por Courtine (2009) e mobilizado por Pêcheux (1999), dialogando com os sociólogos Jean Davallon e Maurice Halbwachs.

Além disso, memória é um conceito discutido por autores da área da linguística, como Pêcheux (1999), e da história, como Le Goff (1990), para citar apenas dois. Por essa razão, achamos mais produtivo e pertinente para os objetivos deste trabalho mobilizar os conceitos de rememoração e comemoração desenvolvidos por Le Goff (1990) no interior de reflexões sobre o conceito de memória nas Ciências Humanas, sobretudo na História e na Antropologia, dando especial atenção à memória coletiva. Compreende-se que a memória coletiva é essencial para a manutenção da identidade de um povo ou nação e, por isso, ela é alvo de disputas de poder diante da preocupação de determinar o que deve ser lembrado e o que deve ser relegado ao esquecimento na operação de manipulação da memória coletiva pelos sujeitos que registram a história.

A memória coletiva, na acepção de Le Goff (1990), liga-se ao domínio dos mitos de origem. Ela descreve e ordena os fatos segundo tradições estabelecidas, voltando-se aos primórdios, aos inícios míticos da tradição. Esse conjunto de fatos históricos são ordenados em narrativas e cronologias de acontecimentos que serão acionados pela memória coletiva por meio da operação de rememoração, que é uma de suas formas de funcionamento. Já a comemoração é compreendida como "a celebração através de um momento comemorativo de um acontecimento memorável" (LE GOFF, 1990, p. 432), podendo assumir diversas formas, como a inscrição, a construção de monumentos, arquivos, bibliotecas, museus, a emissão de documentos, que têm diversas funções na conservação da memória.

Le Goff (1990) considera que a comemoração é um progresso da memória coletiva possibilitado pelo desenvolvimento da escrita. Na atualidade, o jornalista é um profissional da memória e a mídia impressa e a fotografia revolucionaram a operação de comemoração/rememoração da memória coletiva.

Os conceitos abordados nesta seção serão retomados nas análises que passaremos a empreender a seguir.

\section{Discurso como luta e verdade como política: embates em torno da memória coletiva sobre o sujeito quilombola em enunciados da mídia}

As discussões aqui apresentadas são resultantes de uma pesquisa que desenvolvemos (SOUSA, 2020) cujo objetivo era analisar como a mídia participa da construção da identidade 
do sujeito quilombola ao enunciá-lo nas páginas do jornal $O$ Estado do Maranhão. Em nossas discussões, vimos que uma das formas de se enunciar esse sujeito é pela promoção de uma luta entre dois regimes de verdades (FOUCAULT, 2013) acerca da liberdade dos escravizados. Por um lado, alguns enunciados atribuem essa liberdade à assinatura da Lei Áurea pela Princesa Izabel. Por outro lado, há enunciados que concebem a libertação dos escravizados como fruto das intensas lutas dos negros, que resultou na formação de quilombos, dos quais o mais representativo é o de Palmares, localizado na Serra da Barriga, no atual estado de Alagoas (AL).

Dessa forma, o primeiro enunciado que apresentamos para análise é intitulado "No Dia do Negro o preconceito é o grande tema” (O ESTADO DO MARANHÃO, 1983, p. 1).

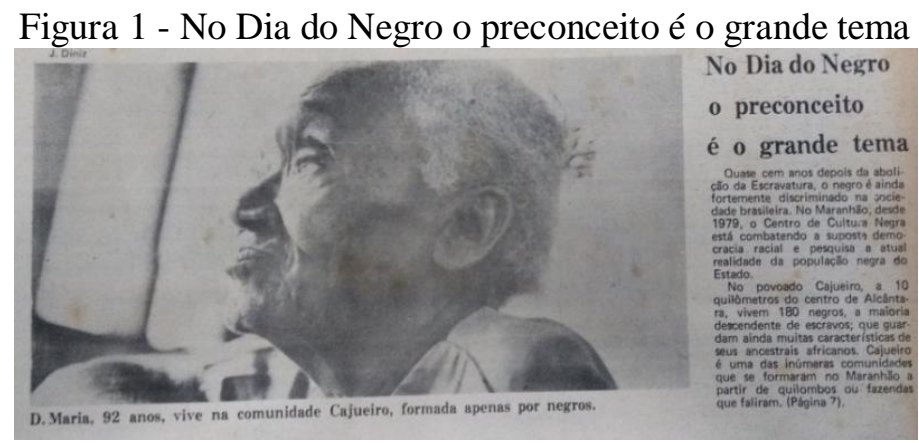

Fonte: O Estado do Maranhão, 13 maio 1983, n. 4137, p. 1

O enunciado possui uma imagem fotográfica de uma idosa identificada como D. Maria, de 92 anos, que vive na comunidade Cajueiro, no município de Alcântara (MA), a qual, de acordo com o enunciado, é "formada apenas por negros”. A seleção da imagem desse sujeito, e não outra em seu lugar, configura uma operação discursiva de credibilizar sua visibilidade, mas não sua enunciação, visto que o regime de verdade (FOUCAULT, 2013) sobre a história das comunidades quilombolas no Brasil que alicerça esse enunciado se apoia na versão oficial da historiografia acerca da libertação dos negros no dia 13 de maio, com a assinatura da Lei Áurea, não na versão sobre o processo de lutas que os levou a habitar esse território.

Essa imagem também nos mostra que o sujeito quilombola não existiu apenas no passado, representado na figura do escravizado fugido, ao mesmo tempo em que concebe o quilombo como uma reunião de negros descendentes diretos de ex-escravizados, concepção que apaga o fato de que, desde o processo de formação, para os quilombos se dirigiam "índios perseguidos, mulatos, curibocas, pessoas perseguidas pela polícia em geral, bandoleiros, devedores do fisco, fugitivos do serviço militar, mulheres sem profissão, brancos pobres e 
prostitutas" (MOURA, 1992, p. 25), formando uma população multiétnica e instalando múltiplas identidades nesse espaço territorial.

$\mathrm{Na}$ época de circulação desse enunciado, as comunidades quilombolas de Alcântara estavam enfrentando uma disputa territorial com a construção do Centro de Lançamento de Alcântara (CLA), situação desencadeada desde o ano de 1980 e que escancara as lutas dos quilombolas contra o sistema capitalista, para o qual são considerados uma formação social atrasada, visto que se caracterizam pelo uso comum das terras cultiváveis e demais recursos naturais, objeto de disputa por seus antagonistas. Alcântara tem uma grande quantidade de comunidades quilombolas, fruto da desagregação de antigas fazendas, de doações de terras como heranças ou abandonadas por seus donos falidos, incluindo ordens religiosas, dentre outras formas de constituição da territorialidade (ALMEIDA, 2008a).

O enunciado em pauta expõe que o discurso acolhido como verdadeiro pelos processos que legitimam sua produção e circulação era aquele que concebia o dia 13 de maio como "o dia do negro". Com a abertura política, a proximidade do centenário da abolição da escravidão e a elaboração da nova Constituição, as comemorações do dia 13 de maio puseram em questão o tema da discriminação racial da população negra, negando o chamado "mito da democracia racial", que muitos atribuem a Gilberto Freyre (2003), para quem os contatos entre os povos que formaram o Brasil não eram de um antagonismo explícito, já que, para ele, houve desagregação de culturas por processos mais sutis e ritmo mais lento do que em outras partes do continente americano. Mesmo reconhecendo que, no Brasil, a comunicação entre os povos não é tão harmônica assim, pois há choques entre as culturas que nos formaram, ele considera que há um "ajustamento de tradições e de tendências raro entre povos formados na mesma circunstância imperialista de colonização moderna dos trópicos” (FREYRE, 2003, p. 231).

Nesse contexto, a luta contra o racismo emerge como forma de negar esse mito da democracia racial e expor a situação das comunidades negras rurais quilombolas naquele momento, constituindo-se em uma forma de comemoração do dia 13 de maio que contesta os seus significados históricos no regime de verdades (FOUCAULT, 2013) oficial sobre a liberdade dos negros. O 13 de maio passou a comemorar o Dia Nacional de Denúncia Contra o Racismo, além de ser confrontado com a comemoração do dia 20 de novembro como dia da Consciência Negra, para rememorar as lutas dos negros por liberdade, e não a pretensa concessão dessa pela classe senhorial.

Os sujeitos que propõem um novo regime de verdade sobre o papel da Princesa Izabel na libertação dos escravizados atribuem a ela um papel simbólico ao oficializar, no dia 13 de 
maio, um fato já consumado, já que a Lei Áurea não mandou extinguir a escravidão, simplesmente a declarou extinta. A abolição foi um processo gerado por campanha em todo o país, durante anos, e, principalmente, pelas lutas dos negros desde muito antes, resultando em mortes e fugas para os quilombos.

No plano jurídico, os antecedentes dessa lei que possibilitaram a libertação dos escravizados foram as leis Euzébio de Queiroz (1850), proibindo o tráfico de negros da África para o Brasil; a lei do Ventre Livre (1871), proibindo a escravização dos negros nascidos no Brasil; e a Lei do Sexagenário (1885), proibindo a escravidão de idosos. Mesmo com esse processo de liberdade, muitos mecanismos foram elaborados para impedir a autonomia desses sujeitos, como a Lei de Terras, de 1850.

Já no terreno socioeconômico, as razões para o fim da escravidão negra no Brasil são: o desenvolvimento econômico por meio da cultura do café e a economia empresarial no Centro Sul; o atraso econômico do Norte e Nordeste, que tornaram o escravizado antilucrativo; a campanha abolicionista, a partir de 1880; a fuga maciça de escravizados, após a Guerra do Paraguai, em 1870; e a conjuntura internacional abolicionista, conforme apontam Assunção (2012) e Almeida (2008b).

Passemos ao segundo enunciado, intitulado "Zumbi: a verdadeira história de Palmares" (O ESTADO DO MARANHÃO, 1988, p. 13). 
Figura 2 - Zumbi: a verdadeira história de Palmares

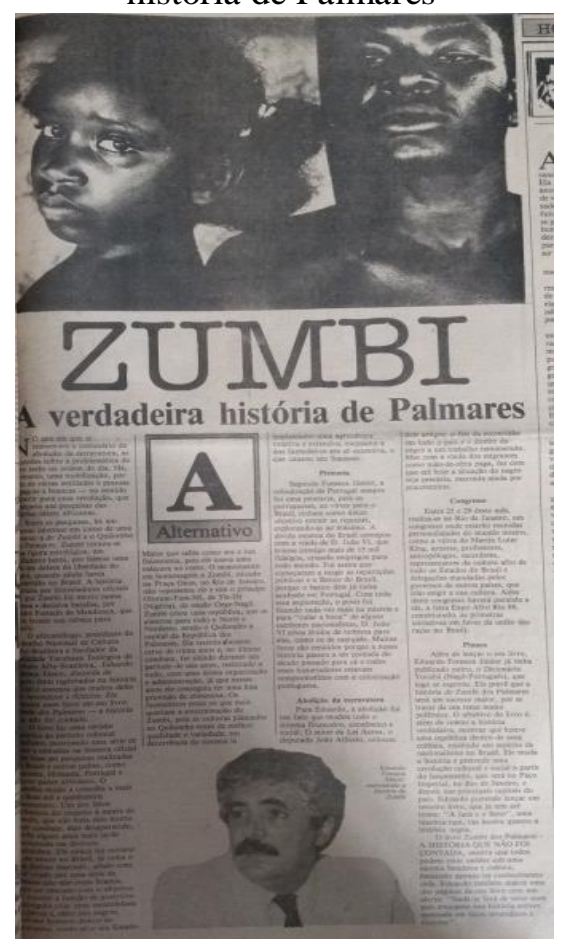

Fonte: $O$ Estado do Maranhão, 12 abr. 1988, n. 8912, p. 13 (Alternativo)

No enunciado em pauta, a história de Zumbi dos Palmares é recontada, propondo uma revisão na história oficial de sua morte, recorrendo ao discurso acadêmico, posto que o enunciado apresenta um livro escrito por Eduardo Fonseca Junior, no qual o autor mostra um compromisso com "a" verdade dos fatos, compreendendo que as versões que foram deixadas para as pessoas acerca desse acontecimento histórico, que foi a luta de Zumbi dos Palmares, foi a versão dos responsáveis por combater a sua organização social e política e que, por isso, não conta a história como de fato teria ocorrido.

Sabe-se que Zumbi era filho da princesa africana Aqualtune, sobrinho de Ganga Zumba e marido de Dandara, com quem teve três (3) filhos. Há versões que afirmam que ele foi criado por um padre. Também não se tem um consenso se Zumbi era uma pessoa ou se era um cargo, e sua morte é tida como um "encantamento" em entidade espiritual.

Dessa forma, em lugar de relativizar essa narrativa, quem fala nesse enunciado de $O$ Estado do Maranhão acredita que está produzindo um documento que é guardião da verdade, que narra a história com objetividade e imparcialidade, tal como a história tradicional se obstina em tentar fazer. Trata-se de um embate entre regimes de verdade (FOUCAULT, 2013) que parte do fato de a história do Brasil ser marcada por omissões de fatos relativos à participação do negro na construção de nossa sociedade, visto que os historiadores do século 
19 que começaram a registrar tal história estavam comprometidos com a colonização portuguesa, o que explica porque os negros exercem o papel de vilões, bárbaros e perdedores nas versões oficiais, ao passo que seus antagonistas são alçados à qualidade de heróis, como ocorreu com Domingos Jorge Velho, bandeirante paulista responsável por abater o quilombo de Palmares, e Luís Alves de Lima e Silva, o Duque de Caxias, responsável por abater os quilombolas na revolta da Balaiada, ocorrida no Maranhão entre 1838 e 1841.

A operação de construção de uma história e memória do Brasil foi realizada pelo Instituto Histórico e Geográfico do Brasil (IHGB), a partir de sua fundação, em 1839, como forma de concretizar um projeto de centralização nacional. Nesse processo, o negro era inferiorizado nas narrativas sobre o processo civilizatório e de construção de um estado nação (SCHWARCZ, 1993). Essa operação de rememoração (LE GOFF, 1990) é hierarquizante, pondo em destaque as contribuições dos povos europeus e impondo uma lei de verdade sobre a identidade do povo brasileiro calcada em uma visão eurocêntrica.

Além disso, ao enunciar sobre o sujeito quilombola, o jornal $O$ Estado do Maranhão mobiliza mecanismos que determinam quem pode falar e o que pode ser dito. Assim, autoriza-se um pesquisador a falar sobre os significados de Palmares, visto que esse sujeito enuncia a partir de um lugar institucional que goza de reconhecimento científico e valorização social como verdadeiro, ao mesmo tempo em que interdita as vozes dos próprios quilombolas, que não são autorizados a dizer o que Palmares ou Zumbi significaram na história do Brasil.

Essa hierarquização entre o sujeito quilombola que vive a história e o cientista que dele fala se materializa no conjunto de fotografias do enunciado, em que vemos duas crianças negras, na parte superior, e o pesquisador, na parte inferior, separados em lados opostos. Assim, o quilombola é interditado do direito a enunciar sobre ele mesmo, mas é posto em visibilidade para credibilizar aquilo que o cientista e o jornalista dizem.

Dessa forma, esse segundo enunciado alinha-se ao regime de verdade (FOUCAULT, 2013) que põe em destaque as lutas dos quilombolas por liberdade e se inscreve em uma operação de comemoração/rememoração (LE GOFF, 1990) do centenário da abolição da escravidão no Brasil e tem como condição de emergência o movimento Nacional Constituinte, que provocou um revisionismo crítico da história do negro na formação da sociedade brasileira. Esse regime discursivo está ligado a diferentes acontecimentos que possibilitaram a sua emergência entre os anos de 1920 e 1980, que destacaremos adiante.

Em 1929, com a ascensão dos movimentos de esquerda e a difusão do pensamento marxista na historiografia e nas ciências sociais, no Brasil, ocorre a primeira interpretação 
classista da luta de Palmares, feita por Astrogildo Pereira e publicada no jornal do Partido Comunista (PC). Essa interpretação é retomada por Décio Freitas e Clóvis Moura.

Os anos de 1930 e 1940 são marcados por interpretações raciais de cunho eugenista e repressões ditatoriais às manifestações do pensamento de esquerda. É no ano de 1944 que Abdias do Nascimento cria o Teatro Experimental do Negro (TEN), propondo a ideia de quilombismo, como movimento de não violência e luta por direito dos negros.

No ano de 1971 ocorre a criação do Grupo Palmares, por militantes de Porto Alegre (RS), em que o quilombo de Palmares é "redescoberto" e se propõe a substituição da comemoração do dia 13 de maio pelo dia 20 de novembro, a realização de eventos anuais, a publicação do Jornal Tição e a revisão da história do negro e de Palmares nos livros didáticos.

Em 1978 ocorre a fundação do Movimento Negro Unificado Contra a Discriminação Racial (MNUCDR, depois reduzido para MNU), também por iniciativa de Abdias do Nascimento. Foi esse movimento que propôs considerar o dia 20 de novembro como o Dia Nacional da Consciência Negra. Nesse contexto, emerge uma geração de militantes negros que denunciam as violências policiais contra a população negra.

Em 1979 ocorre a criação do Centro de Cultura Negra do Maranhão (CCN), que criou o Projeto Vida de Negro (PVN), junto com a Sociedade Maranhense para a Defesa dos Direitos Humanos (SMDDH), iniciado no ano de 1988, para mapear e solucionar conflitos agrários envolvendo comunidades quilombolas no estado.

Já em 1981 foi celebrada a Missa dos Quilombos, em Recife, na qual altos representantes da Igreja Católica se penitenciaram e pediram perdão pelo posicionamento adotado historicamente pela Igreja em relação aos negros, à África e aos quilombolas, concebidos como os maiores inimigos dos ideais cristãos por séculos.

Nesse mesmo ano, ocorreram discussões na Fundação Pró-Memória acerca dos "Monumentos Negros", que resultaram no tombamento do primeiro patrimônio histórico e cultural nacional, que foi o Terreiro de Candomblé da Casa Branca, em Salvador, Bahia (BA), e da Serra da Barriga, na União dos Palmares, Alagoas (AL), como sítio histórico. Esses atos de rememoração (LE GOFF, 1990) inscrevem a memória do negro na história do Brasil, como resultado de lutas pela memória social.

Em 1984 foi lançado o filme "Quilombo", de Cacá Diegues, contando a história de Palmares e Zumbi com base nos escritos de João Felício dos Santos e de Décio de Freitas. O filme traça a história de chegada dos quilombolas a Palmares, a partir de 1650, as Lutas de Ganga Zumba, Dandara, Acotirene, Acaiuba e Zumbi contra as tropas de Domingos Jorge 
Velho e a morte de Zumbi, com seu posterior "encantamento", ou seja, transformação em entidade religiosa afro-brasileira. Esse filme também auxiliou a criar uma memória sobre as lutas de Zumbi dos Palmares e inscrevê-las na história da formação do povo brasileiro.

Finalmente, o ano de 1988 foi marcado por uma intensa realização de "eventos" em âmbito nacional com o fito de comemorar, criticar, repensar, negar o centenário da abolição da escravidão e a situação do negro no Brasil. Nesse momento, não havia discussões sobre as comunidades quilombolas tal como as conhecemos na atualidade, apenas referências ao quilombo de Palmares e à figura de Zumbi, relegando-se ao esquecimento a figura do sujeito quilombola do cotidiano.

Esse conjunto de acontecimentos promoveu deslocamentos discursivos sobre a abolição, sobre a exaltação dos vultos nacionais abolicionistas, a discriminação racial e sobre a ideia da democracia racial. Tais questões representam as condições de emergência dos dois enunciados analisados, nos quais temos o embate entre dois regimes de verdade (FOUCAULT, 2013) acerca do sujeito quilombola, sua luta pela liberdade e sua participação na história de formação do Brasil, determinado também quem poderia falar sobre esse tema e quais enunciados seriam acolhidos como verdadeiros em nossa época.

Atualmente, as lutas desses sujeitos por reconhecimento étnico racial e direitos sociais esbarram justamente nos regimes de verdade que os colocam em posição hierárquica de subcidadãos, derivadas dos discursos raciais que consideram os negros inferiores em termos de capacidade intelectual e moral, visto que são considerados perigosos e com tendência à criminalidade. É isso que se observa, por exemplo, no vídeo com falas do Presidente Jair Bolsonaro sobre quilombolas, citado na introdução, no qual ele contesta o que chama de “entregar as riquezas do Brasil” a esses sujeitos.

Tais questões nos mostram a necessidade de ouvir o que esses sujeitos falam sobre si e fazer circular na mídia saberes e regimes discursivos acerca da sua experiência na história do Brasil, como ocorreu no ano de 2019, por iniciativa da TV Justiça, ao produzir o documentário "Quilombos do século XXI", no qual quilombolas puderam discutir sobre o racismo estrutural no Brasil desde o fim do regime escravista, em 1888, os mecanismos de imobilização desencadeados no plano legal desde o Império e suas consequências para a emancipação dos negros, tal como discutimos em outro trabalho. 


\section{Considerações finais}

Ao nos interrogarmos sobre os regimes de verdade que sustentam a produção enunciativa da mídia acerca do sujeito quilombola, recorremos a dois enunciados do jornal $O$ Estado do Maranhão dos anos de 1980. Nossas discussões mostraram que há, na instância da mídia, procedimentos de controle do discurso que gerenciam o que deve ser dito e circular como verdade e quem são os sujeitos autorizados a enunciar tais verdades, segundo critérios historicamente elaborados para determinar o verdadeiro de cada época.

No que concerne à participação do sujeito quilombola na formação da sociedade brasileira, há uma disputa pela manipulação da memória social sobre esse sujeito, que gira em torno da sua liberdade como resultante de um ato da classe senhorial, ao ser assinada, no dia 13 de maio de 1888, uma lei que declarava extinto o regime escravista, ou como resultado das lutas por liberdade travadas ao longo de muitos anos, resultando na fuga de muitos escravizados para zonas de matas, onde se constituíram quilombos.

O jornalista, ao apresentar esses fatos, comporta-se como um "profissional da memória”, pois promove o resgate desses regimes de verdade em épocas pré-definidas, pondo em circulação regimes de verdades que estão ligados a diferentes acontecimentos da história, mas que são recontados por sujeitos que se colocam como porta vozes de um discurso que se propõe revelar "a" verdade, elidindo, assim, o fato de que a verdade é uma construção histórica.

\section{Referências}

ALMEIDA, Alfredo Wagner Berno de. Terras de preto, terras de santo, terras de índio: uso comum e conflito. In: Terra de quilombo, terras indígenas, "babaçuais livre", "castanhais do povo", faixinais e fundos de pasto: terras tradicionalmente ocupadas. 2 ed. Manaus: PGSCA-UFAM, 2008a, p. 133-178.

ALMEIDA, Alfredo Wagner Berno de. A ideologia da decadência: leitura antropológica a uma história de agricultura do Maranhão. 2 ed. Rio de Janeiro: Editora Casa 8 / Fundação Universidade do Amazonas, 2008b.

ASSUNÇÃO, Matthias Röhrig. Quilombos maranhenses. In: REIS, João José; GOMES, Flávio dos Santos. Liberdade por um fio: história dos quilombos no Brasil. São Paulo: Claro Enigma, 2012, p. 9-28. 
COURTINE, Jean-Jacques. Análise do Discurso Político: o discurso comunista endereçado aos cristãos. Tradução Bacharéis em Letras pela Universidade Federal do Rio Grande do Sul. São Carlos, SP: EdUFSCar, 2009.

DOCUMENTÁRIO - Quilombos do século XXI. [S. 1.: s. n.], 2019. 1 vídeo (25 min 04 seg). Publicado pelo canal TV Justiça Oficial. Disponível em: <https://www.youtube.com/watch?v=CNhqvWJjGII>. Acesso em: 01 fev. 2020.

FOUCAULT, Michel. A verdade e as formas jurídicas. Tradução Roberto Cabral de Melo Machado e Eduardo jardim Morais. Rio de Janeiro: NAU Editora, 2002.

FOUCAULT, Michel. A arqueologia do saber. Tradução Luiz Felipe Baeta Neves. 7 ed. Rio de Janeiro: Forense Universitária, 2008.

FOUCAULT, Michel. Verdade e poder. In: Microfísica do poder. Tradução Roberto Machado. 26 ed. São Paulo: Graal, 2013a, p. 35-54.

FREYRE, Gilberto. Casa-grande \& senzala: formação da família brasileira sob o regime da economia patriarcal. 48 ed. São Paulo: Global, 2003.

GOMES, Flávio dos Santos. Mocambos e quilombos: uma história do campesinato negro no Brasil. São Paulo: Claro Enigma, 2015.

LE GOFF, Jacques. História e memória. Tradução Bernardo Leitão. Campinas, SP: Editora da UNICAMP, 1990.

MOURA, Clóvis. História do negro brasileiro. São Paulo: Editora Ática, 1992.

NEGRO Quilombola não serve nem para procriar!. [S. 1.: s. n.], 2017. 1 vídeo (53 seg). Publicado pelo canal Sos Racismo Brasil. Disponível em: <https://www.youtube.com/watch?v=ks0dgE8jpkw>. Acesso em: 01 fev. 2020.

PÊCHEUX, Michel. Papel da memória. In: ACHARD, Pierre et al. Papel da Memória. Tradução José Horta Nunes. Campinas, SP: Pontes, 1999, p. 49-57.

QUILOMBO. [S. 1.: s. n.], 2015. 1 vídeo (1h $54 \mathrm{~min} 30 \mathrm{seg}$ ). Publicado pelo canal 2as Marias conhecimento. Disponível em: <https://www.youtube.com/watch?v=SQEMAPIa6uk>. Acesso em: 01 fev. 2020.

REIS, João José; GOMES, Flávio dos Santos. Introdução: uma história de liberdade. In: Liberdade por um fio: história dos quilombos no Brasil. São Paulo: Claro Enigma, 2012, p. 9-28.

SCHWARCZ, Lilia Moritz. O espetáculo das raças: cientistas, instituições e questão racial no Brasil (1870-1930). São Paulo: Companhia das Letras, 1993.

SOUSA, Claudemir; SILVA, Francisco Vieira; PEREIRA, Tânia Maria Augusto. A noçãoconceito de memória em análise do discurso: um percurso teórico-metodológico. In: CUTRIM, Ilza Galvão; CRUZ, Monica da Silva Visadas discursivas: identidades, memórias e culturas artísticas. São Luís: EDUFMA, 2016, p. 99-117. 
SOUSA, Claudemir. Discurso, mídia e identidade: uma arqueogenealogia do sujeito quilombola nas páginas do jornal O Estado do Maranhão. 2020. 345 f. Tese (Doutorado) Faculdade de Ciências e Letras, Universidade Estadual Paulista Júlio de Mesquita Filho, Araraquara, 2020.

Recebido em: 1 de abril de 2020.

Aceito em: 30 de abril de 2020. 